local origin, by the limited scope of the existing regional advisory councils and by the advantage, from the point of view of staff, of the relatively small organization of a region over that of London. It was less impressed by demand for autonomy voiced both in Scotland and in Wales, though it recognized the dangers which could attend excessive centralization. But in its concern not to break British broadcasting into fragments, it does not appear to have pursued the idea of federation sufficiently, or to have provided for the regional devolution in England which is equally, if not more, important than in the three regions suggested, if the full regional contribution is to be secured.

The regional development of broadcasting is attended with certain technical difficulties on the financial side, which may make it of less general interest from the administrative point of view than most aspects of the Corporation's organization. The extent to which the Corporation has so far been independent of the political field also makes its experience rather less relevant to that of other experiments in public ownership and control, though exploration of the issue of Ministerial responsibility as recommended might be illuminating. Nevertheless, there is much in this report that bears closely on the problems which the nationalized industries are now facing, and some of these are to be found in the minority report and in the notes and reservations of individual members of the Cormmittee which are appended.

Few big public or private corporations could have emerged, as the British Broadcasting Corporation has done, from so searching an inquiry with such credit, but if the future is to show as distinguished a record, there must be no lack of the stimulus of informed and constructive criticism. No matter how excellent the internal organization of such a body, such criticism is the ultimate safeguard against abuse of power, and above all is the final means by which we can ensure that broadcasting is fully developed and utilized to assist a democracy to understand the issues upon which it may be required to vote or act.

\section{REFERENCE-BOOK OF DAIRYING}

A Dictionary of Dairying

By Dr. J. G. Davis. ${ }^{\circ}$ P. $x x+856+76$ plates. (London: Leonard Hill, Ltd., 1950.) 37s. 6d.

7 HERE has always been a dearth of British text-books on dairying, apart from works dealing with particular branches such as dairy husbandry, dairy chemistry and dairy bacteriology. In view of the extensive literature now devoted to publication of original work in the fields of dairy science and technology, the lack of complementary standard text-books is felt acutely by investigators, teachers and practical dairy workers. Certainly there is a wide choice of American text-books; but unfortunately many of these are inadequate, and all refer to conditions which frequently differ from those met with in Great Britain. In a single volume, Dr. J. G. Davis and his twenty-eight collaborators have now amassed the broad fundamentals of modern dairying, covering the scientific, technological and economic aspects. True, this is not a text-book, but rather, as the title indicates, a work of reference arranged alphabetically; nevertheless, it will be very widely used.

In an omnibus work of this character considerable variation in treatment is almost inevitable, and consequently there are differences in quality botween the various sections. Some subjects are accorded the briefest-occasionally superficial-reference, while others (particularly contributed sections) receive an approach to detailed text-book treatment. Purely scientific matters are, perhaps, accorded the major emphasis. In order to confine the whole field of dairying within restricted bounds, most subjects have, very wisely, been limited to the bare minimum. Nevertheless, the information given is basically sound and readily intelligible ; in addition, numerous crossreferences are employed and further sources of detailed information are indicated.

Certain fields wherein the existing literature is deficient or confusing have been selected for more detailed treatment. In his choice of such material the author has on the whole been very happy. Thus, it is particularly pleasing to find useful sections dealing with milk-bottle fillers, bottle washing, and the problems of detergency in dairy practice. Some of the material presented in the sections on dairy management and the costing of milk distributive operations is also original and will no doubt provoke discussion. Other relatively long sections deal with the isolation and identification of lactic acid bacteria, coliform bacteria, thermophilic and thermoduric bacteria, bacteriological grading of milk, cleansing and sterilization of dairy plant, water supplies for dairy premises, dairy effluent disposal, cooling of milk at the farm, the pasteurization of milk, and the manufacture of ice crearn, cheese, condensed milk and dried milk. The summaries of recent research findings in these fields will be valuable to many. Dairy bacteriology tends to receive more emphasis than does dairy chemistry, but this is the present fashion.

Notwithstanding the immense labour involved in the production of this volume, a few further additions may perhaps be suggested. The essential dairy services might receive more generous treatment; thus steam raising, a basic requirement of all dairy operations, is scarcely mentioned and the references given are inadequate, while the use of electric power for dairy purposes is accorded similar treatment. A special section on the design of dairy buildings and the lay-out of plant would be valuable. It is surprising to find little information on the general properties, processing and marketing of liquid cream ; in spite of present restrictions in Britain, cream production is an important dairying activity which merits more extended treatment. The production of infant foods, which absorbs large quantities of milk, might also find a place. The problems of milk transport other than retail delivery, and the design and standardization of milk containers are other important matters which deserve fuller discussion. Throughout the book a more generous use of explanatory diagrams, as opposed to illustrations, would assist non-expert readers. These omissions are relatively small matters which can be put right in future editions.

The "Dictionary" will undoubtedly become a standard work of reference. Indeed, the appearance of this encyclopædic volume (at an unusually modest price) is quite an event in the dairying world.

E. L. Crossley 